\title{
Systolic Dyssynchrony Index derived from cardiac magnetic resonance imaging predicts left ventricular remodeling in heart failure patients undergoing CRT
}

\author{
Simon G Duckett ${ }^{\text {* }}$, Matthew R Ginks' ${ }^{1}$, Anoop K Shetty ${ }^{1}$, Matthias Paul ${ }^{1}$, Stam Kapetanakis ${ }^{2}$, Stephen Sinclair ${ }^{1}$, \\ Tobias Schaeffter ${ }^{1}$, C Aldo Rinaldi ${ }^{2}$, Gerry Carr-White ${ }^{2}$, Reza Razavi ${ }^{1}$
}

From 2011 SCMR/Euro CMR Joint Scientific Sessions

Nice, France. 3-6 February 2011

\section{Introduction}

It is known that $30-40 \%$ of heart failure patients that undergo cardiac resynchronization therapy (CRT) do not derive significant clinical benefit. Using cine imaging a measure of volume change over the cardiac cycle can be derived called the Systolic Dyssynchrony Index (SDI). This has the potential to improve patient selection pre CRT.

\section{Purpose}

We assessed the potential of the SDI derived from CMR to predict reduction in end systolic volume (ESV) and improvement in ejection fraction in heart failure patients undergoing CRT.

\section{Method}

42 heart failure patients ( 38 male, ejection fraction 26 $\pm 8.9 \%$, NYHA $2.8 \pm 0.4$ ), 21 with ischemic cardiomyopathy (ICM) and 21 with dilated cardiomyopathy (DCM) underwent a CMR prior to CRT implantation. Patients were scanned using 1.5T MR-scanner (Achieva, Philips Healthcare, Best, Netherlands) with either 32 or 5-element cardiac coil. Cine steady state free precession (cine-SSFP) images of four, three, two chamber as well as a multiple slice short axis stack were acquired $\left(\mathrm{FA}=60^{\circ}, \mathrm{TR} / \mathrm{TE}=2.9 / 1.5 \mathrm{~ms}\right.$, resolution $2.2 \times 2.2 \times 10 \mathrm{~mm}$, 30 heart phases). Using TomTec 4D LV-Analysis MR (TT4DMR) we derived a 16 segment systolic dyssynchrony index (SDI). 2D echo pre and 6 months post

\footnotetext{
${ }^{1}$ Kings College London, London, UK
}

Full list of author information is available at the end of the article
CRT implantation was used to assess change in EF and ESV. Patients were considered to have remodeled if there was $15 \%$ reduction in ESV. Furthermore $\geq 15 \%$ improvement in EF was also considered as responding to CRT. An SDI of $10.3 \%$ was used to calculate sensitivity and specificities.

\section{Results}

All patients had a CRT device and were followed up at 6 months. 19 (45\%) of the patients had a reduction in ESV $\geq 15 \%$ and $22(52 \%)$ had an improvement in EF of $\geq 15 \%$. There was a highly significant relationship between reduction in ESV and SDI $(\mathrm{P}<0.0001)$ as well as a greater than $15 \%$ improvement in EF and SDI $(\mathrm{P}<0.0001)$ (see figure 1 and table 1$)$. The sensitivity and specificity for CMR derived SDI to predict a $15 \%$ reduction in ESV was 0.88 and 0.91 respectively (positive predictive value 0.88 , negative predictive value 0.91). The sensitivity and specificity for CMR derived SDI to predict a $15 \%$ increase in EF was 0.76 and 0.94

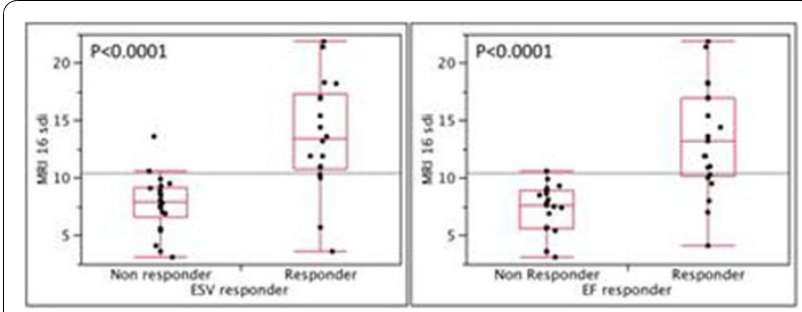

Figure 1 Shows relationship between a percentage SDI and presence of reverse remodeling on the basis of LV end-systolic volume (ESV) (left) and LV EF (right). 
Table 1 Shows the change in ESV and EF pre and post CRT

\begin{tabular}{lllllll}
\hline All patients & All patients & & \multicolumn{2}{l}{ Patients with SDI $>$ 10.3 } & \multicolumn{2}{l}{ Patients with SDI < 10.3 } \\
\hline & Pre CRT & Post CRT & Pre CRT & Post CRT & Pre CRT & Post CRT \\
\hline Ejection Fraction (\%) & $26 \pm 8.9$ & $31.8 \pm 9.9 \mathrm{P}=0.0005$ & $21.7 \pm 8.4$ & $34.9 \pm 7.8 \mathrm{P}<0.0001$ & $28.9 \pm 7.9$ & $28.3 \pm 7.7 \mathrm{~N} / \mathrm{S}$ \\
End Systolic Volume $(\mathrm{ml})$ & $171 \pm 65$ & $157 \pm 66 \mathrm{P}=0.03$ & $197 \pm 74$ & $145 \pm 55 \mathrm{P}<0.0001$ & $154 \pm 54$ & $167 \pm 67 \mathrm{~N} / \mathrm{S}$ \\
\hline
\end{tabular}

respectively (positive predictive value 0.94 , negative predictive value 0.77 ).

\section{Conclusion}

SDI derived from CMR is highly predictive at selecting which patients are likely to remodel post CRT. This may be clinically useful to help identify which patients are likely to responders to CRT.

Author details

${ }^{1}$ Kings College London, London, UK. ' Guy's and St Thomas' Hospital,

London, UK

Published: 2 February 2011

doi:10.1186/1532-429X-13-S1-P175

Cite this article as: Duckett et al: Systolic Dyssynchrony Index derived

from cardiac magnetic resonance imaging predicts left ventricular

remodeling in heart failure patients undergoing CRT. Journal of

Cardiovascular Magnetic Resonance 2011 13(Suppl 1):P175.

Submit your next manuscript to BioMed Central and take full advantage of:

- Convenient online submission

- Thorough peer review

- No space constraints or color figure charges

- Immediate publication on acceptance

- Inclusion in PubMed, CAS, Scopus and Google Scholar

- Research which is freely available for redistribution

Submit your manuscript at www.biomedcentral.com/submit 